\title{
The relationship between cognitive and somatic measures in the assessment of anxiety
}

\author{
MICHAEL A. CRABBS \\ University of Houston at Clear Lake City, Houston, Texas 77058 \\ and \\ GORDON HOPPER \\ Iowa State University, Ames, Iowa 50011
}

\begin{abstract}
The purpose of this study was to establish the extent and direction of the relationship between physiological and self-report measures of anxiety. Helping-profession trainees' responses at rest, in anticipation of a stressful situation, and during the stressful situation were monitored with electromyography and finger temperature instruments. The State-Trait Anxiety Inventory was administered at the conclusion of each of the three data collection phases. The results did not reveal a relationship among the three distinct assessment modalities during any phase of the study. In general, the Pearson produce-moment correlation coefficients were so small as to say little about the strength or direction. However, the relationship of each assessment modality with itself in later phases of the study was significant at the .01 level.
\end{abstract}

The concept of anxiety holds a central position in many theories of behavior and/or personality. Because so much human behavior is thought to be affected by this emotion, many attempts have been made to define this term (Cattell \& Scheier, 1958). Psychophysiological researchers have sought to establish the debilitating nature of the anxiety experience. Early findings suggest a pattern of individual responses associated with this arousal state. Significant changes in heart rate (Ax, 1953; Schachter, 1957), muscle tension (Ax, 1953; Martin, 1961), hand temperature (Schachter, 1957; Wenger, 1957), and galvanic skin response (Ax, 1953; Martin, 1961) have occurred in research subjects when confronted with an anxiety-producing stimulus. The more recent work of Brown $(1974,1977)$, Davidson and Schwartz (1976), and Green, Green, and Walters (1970) has confirmed these preliminary findings. However, one should not infer that autonomic changes will occur in a similar pattern for all individuals (Lacey, 1950).

In addition to the somatic dimensions described above, anxiety may also be experienced as cognitive or mental turmoil. The most popular device for the measurement of cognitive anxiety remains the inventory, scale, or questionnaire. Levitt (1967) describes 10 selfreport instruments in common use within psychological research. The accumulated body of research data indicates that these instruments provide valid anxiety change measures in response to experimental or real-life stress (Davidson \& Schwartz, 1976; Levitt, 1967; Spielberger, 1972).

One might assume that there would be cause to believe that substantial correlations exist between physiological and psychological measures of anxiety. However, Martin (1961, p. 243) reports that "research . . . gives little ground for optimism that these variables will correlate very highly, if at all." It is apparent from recent research studies that this psychophysiological issue has not been adequately resolved. While Eysenck (1975) and others (Bloom \& Trautt, 1977; Kelly, Brown, \& Shaffer, 1970) have addressed this issue and found significant correlations, Brown (1977), Leboeuf (1977), and Rachman (1968) have failed to draw similar conclusions. The purpose of this study was to explore the relationship that exists between two physiological measures (i.e., electromyography and finger temperature) and a self-report measure (i.e., State-Trait Anxiety Inventory, STAI) of anxiety for helping-profession trainees during an initial interview.

\section{METHOD}

Subjects

Subjects in this experiment were 24 volunteer undergraduate and graduate students (mean age $=27.2$ years) enrolled in a helping-profession curriculum (i.e., psychology or counselor education). Although the volunteers had prior interest in the helping professions, they were all in the preliminary stages of their training. Prior to participation in the procedures of this research, subjects were administered the A-Trait scale of the STAI (Spielberger, Gorsuch, \& Lushene, 1970). The results of the subjects' performance on this were used as the dependent variables in several preliminary statistical tests. The fact that the independent variables of age, sex, and graduate or undergraduate status proved to be nonsignificant is reported elsewhere (Crabbs, 1979).

\section{Apparatus and Instruments-Physiological}

The somatic dimension of anxiety was measured by electromyographic (EMG) and finger temperature levels. An EMG feedback monitor (EDC-22) manufactured by Extended Digital Concepts was used. Nondominant forearm muscle tension signals measured by silver/silver chloride electrodes (DC-6) were ampli- 
fied by a differential amplifier input stage. The signals then passed to a rectifier/integrator circuit, where they were averaged and displayed on a meter. The EDC- 22 has a sensitivity of 2 microVpp and a threshold level from 2.5 microV up.

The Cyborg feedback thermometer (Model J42) was used to record finger temperature. Using the nondominant index finger as the measurement site, the subject was connected to the instrument by a tiny temperature probe (thermistor) taped comfortably to the finger. The J42 is completely automatic; it tracks absolute temperature continuously at resolution up to $.01^{\circ} \mathrm{F}$. The $\mathrm{J} 42$ has a temperature range of $23^{\circ} \mathrm{F}-113^{\circ} \mathrm{F}$, with an accuracy of $\pm .3^{\circ} \mathrm{F}$.

\section{Apparatus and Instruments-Self-Report}

The STAI (Spielberger, et al., 1970) was used to assess those unwanted verbal or visual-spatial cognitions indicative of cognitive anxiety. This paper-and-pencil instrument is composed of two scales: A-Trait and A-State. The former scale consists of 20 questions that ask subjects to describe how they feel generally (i.e., reflecting tendencies toward anxiety); the latter scale also consists of 20 questions, but it requires subjects to indicate how they feel at a particular time (i.e., situational anxiety). There are no time limits for this instrument, although college students can usually complete both scales in less than $15 \mathrm{~min}$ (Spielberger et al., 1970). The STAI was selected because it permits the experimenter to control for the effects of age, sex, and graduate or undergraduate status upon one's predisposition toward anxiety; it also measures subjects' responses during a stimulus condition. Finally, this instrument is composed of more cognitive items than other self-report measures of anxiety (Davidson \& Schwartz, 1976), and the reliability and validity coefficients are well within the required tolerance (.73-.92).

\section{Procedure}

Each subject was seen individually for approximately $45 \mathrm{~min}$. Upon arriving at the laboratory, the participants were first familiarized with the experimental environment, an $8 \times 8 \mathrm{ft}$ room that contained the requisite equipment, seating, and a one-way observational mirror. Following this, subjects were given a brief description of the experiment. In each session, there were three phases. The first, or "baseline," phase allowed subjects to become accustomed to the environment. To obtain baseline EMG and finger temperature under standard conditions, a $10 \mathrm{~min}$ film (University of Iowa, 1965), selected to produce neutral stimuli, was shown to all subjects. During the movie, physiological readings were recorded at 3-min intervals. The readings were later averaged to produce an average baseline measure on each physiological dimension for the participants. Upon conclusion of the film, subjects completed the A-State scale of the STAI.

The second, or "induction," phase began when subjects were informed that they would be conducting a 15 -min initial interview with a prospective client of the campus counseling service. Upon completion of the verbal instructions, participants were left alone to prepare as they wished. During this time the experimenter monitored the subjects' EMG and finger temperature levels at 1,3 , and $5 \mathrm{~min}$. These readings were subsequently averaged and reserved for later analysis. After this 5-min induction phase, the subjects were informed that the client had arrived and was waiting in the outside hallway. The A-State scale of the STAI was administered before the subject was introduced to the client.

The third or "interview" phase began with the introduction of the client to each subject. In order to standardize this phase, the client was a confederate who had spent $3 \mathrm{~h}$ in training to present a relatively neutral problem. The experimenter left the room to monitor the physiological instruments for the duration of the 15-min period. Readings were recorded at 3-min intervals and were later averaged for both EMG and finger temperature. At the end of $15-\mathrm{min}$, the experimenter entered the interview room, dismissed the client, and instructed the subject on the completion of the A-State scale of the STAI.

\section{RESULTS}

In order to establish the relationship between the two physiological and one self-report measures of state anxiety, Pearson product-moment correlation coefficients were calculated. The correlation coefficient was calculated between the dependent variables-self-report (i.e., A-State scale of the STAI) and physiological (i.e., EMG and finger temperature) assessments of anxiety-for each of the three phases (baseline, induction, and interview) in the research. (With 22 degrees of freedom, a Pearson's $r$ of .40 was necessary to reach statistical significance at the .05 level and establish a relationship.) These data are presented in Table 1 in matrix form to depict the dependent variables' relationships to each other in each of the three research phases.

The matrix in Table 1 reflects data of two types: (1) the relationship between each distinct assessment modality (i.e., EMG, finger temperature, and self-report) during each phase, and (2) the relationship of each assessment modality with itself in a later phase (i.e., EMG in each of the three phases). When considering the first type of data, it is apparent that no significant relationships were established between each distinct assessment modality. Using the largest correlation $(r=$ .32 for EMG with finger temperature in the interview phase), only $10.2 \%$ of the variability was shared between the two variables. The remaining correlation coefficients

Table 1

Pearson Product-Moment Correlation Coefficients for Three Dependent Variables Within Each Phase

\begin{tabular}{lccccccccc}
\hline & B1 & B2 & B3 & I1 & I2 & I3 & T1 & T2 & T3 \\
\hline B1 & 1.00 & & & & & & & & \\
B2 & .16 & 1.00 & & & & & & & \\
B3 & -.13 & -.07 & 1.00 & & & & & & \\
I1 & $.93^{*}$ & .11 & -.12 & 1.00 & & & & \\
I2 & .16 & $.95 *$ & -.07 & .11 & 1.00 & & & \\
I3 & -.06 & -.04 & $.74 *$ & .05 & -.11 & 1.00 & & \\
T1 & $.92^{*}$ & .17 & -.04 & $.91^{*}$ & .19 & .08 & 1.00 & & \\
T2 & .32 & $.83^{*}$ & -.08 & .26 & $.93^{*}$ & -.15 & .32 & 1.00 & 1.00 \\
T3 & -.11 & .04 & $.60^{*}$ & -.12 & .02 & $.66^{*}$ & .03 & -.02 & 1.00 \\
\hline
\end{tabular}

Note-B1 = baseline $E M G ; B 2=$ baseline finger temperature $; B 3=$ baseline $A$-state scale performance $; I=$ induction EMG $\cdot I 2=$ induction finger temperature; $I 3=$ induction $A$-state scale performance; $T 1=$ interview $E M G ; T 2=$ Interview finger temperature; $T 3=$ interview $A$-state scale performance. $\quad$ *Significant at the .01 level. 
of these data were nonsignificant; they were also so small as to say very little about the strength or direction of the relationship.

The most interesting finding reflects the relationship of each assessment modality with itself in each of the three phases of this research. The Pearson productmoment correlation coefficient indicated that there was a direct positive relationship of each assessment measure with itself during the baseline, induction, and interview phases. The strength of these correlations was apparent, with from $36 \%$ to $90 \%$ of the variance shared. Interestingly, the coefficients were much stronger for the physiological, or somatic, assessment procedures than for the cognitive, or self-report, measure. From these results, it was concluded that there was a significant positive relationship between a subject's initial level of state anxiety and later measures on that same dimension.

\section{DISCUSSION}

Because previous investigations have produced conflicting results, this research was undertaken to determine the nature and degree of the relationship between physiological and self-report measures of anxiety. The findings confirm the early assertions of Martin (1961) that correlations between anxiety assessment modalities during rest and arousal would be negligible. More recent investigators have obtained similar results (Bowman, Roberts, \& Giesen, 1978; Leboeuf, 1977; Rachman, 1968), but none structured the data collection procedures in the same manner. The three phases of the research (baseline, induction, and interview) permitted the examination of the anxiety response at rest, in anticipation of a stressful situation, and during the stressful situation. These procedures minimize the criticism that experimentally induced conditions have little similarity to real-life anxiety-evoking situations. In this research, the procedures were consistent with actual training activities for helping professionals.

It is apparent that the two assessment modalities (i.e., physiological, or somatic, and self-report, or cognitive) behave in an independent but parallel fashion. The results are conclusive in establishing the positive relationship for each across the three phases. Bowman et al. (1978), while arriving at similar conclusions, speculated that predictions of responses to stressful situations are best accomplished if limited to the same assessment modality. Hence, baseline finger temperature measures will serve as good predictors of trainees' finger temperatures following instructions for a helping interview and during the interview itself.

The independent but parallel nature of the anxiety response has been found in this research. However, it is difficult to speculate on the reasons for this finding. Lang (1971) proposed that response dimensions arise from different brain centers and this results in behaviors that function partially independently. Martin (1961) believed that stressful situations may be interpreted differently by individuals. However, the findings of the present research lend support for the conclusions drawn by Davidson and Schwartz (1976). They speculated that the anxiety response may be mode specific, that is, experienced somatically and/or cognitively. The present research has served to establish that some subjects appear to have an awareness of one dimension exclusive of the other, whereas other subjects are moderately aware of both dimensions. At best, it can be concluded that the relationship between anxiety assessment measures is dependent upon a diverse set of variables: the subject (including a wide range of personality factors and response patterns), the stimulus condition, the appropriateness of the assessment measures to the subject, and the accuracy of the instruments measuring anxiety.
Research in the future should be directed toward the resolution of the tentativeness of this conclusion.

\section{REFERENCES}

Ax, A. F. The physiological differentiation between fear and anger in humans. Psychosomatic Medicine, 1953, 15, 433-442.

Bloom, L. J., \& TrautT, G. M. Finger pulse volume as a measure of anxiety: Further evaluation. Psychophysiology, 1977, 14, $541-544$

Bowman, J. T., Roberts, G. T., \& Giesen, J. M. Counselor trainee anxiety during the initial counseling interview. Journal of Counseling Psychology, 1978, 25, 137-143.

Brown, B. B. New mind, new body. New York: Harper \& Row, 1974.

Brown, B. B. Stress and the art of biofeedback. New York: Harper \& Row, 1977.

Cattell, R. B., \& Scheier, I. H. The nature of anxiety: A review of thirteen multivariate analyses comprising 814 variables. Psychological Reports, 1958, 4, 351-388.

Crabrs, M. A. The induction and attenuation of state anxiety in helping profession trainees during the initial counseling interview. Unpublished doctoral dissertation, Iowa State University, 1979.

Davidson, R. J., \& Schwartz, G. E. The psychobiology of relaxation and related states: A multi-process theory. In D. I. Mostofsky (Ed.), Behavior control and modification of physiological activity. Englewood Cliffs, N.J: Prentice-Hall, 1976.

EysEnck, H. J. The measurement of emotion: Psychological parameters and methods. In L. Levi (Ed.), Emotions-Their parameters and measurement. New York: Raven Press, 1975.

University of Iowa (Producer). Fluid image. Iowa City, Iowa: University of Iowa Press, 1965. (Film)

Green, E., Green, A., \& Walters, E. Voluntary control of internal states: Psychological and physiological. Journal of Transpersonal Psychology, 1970, 1, 1-26.

Kelly, D., Brown, C. C., \& Shaffer, J. W. A comparison of physiological and psychological measurements on anxious patients and normal controls. Psychophysiology, 1970, 6, 429-441.

LACEY, J. I. Individual difference in somatic response patterns. Journal of Comparative Physiological Psychology, 1950, 43, 338-350.

LANG, R. J. The application of psychophysiological methods to the study of psychotherapy and behavior. In A. E. Bergin \& S. L. Garfield (Eds.), Handbook of psychotherapy and behavior change. New York: Wiley, 1971.

Leboeuf, A. The effects of EMG feedback training on state anxiety in introverts and extraverts. Journal of Clinical Psychology, 1977, 33, 251-253.

LEvitT, E. E. The psychology of anxiety. New York: Bobbs Merrill, 1967.

Martin, B. The assessment of anxiety by physiological behavioral measures. Psychological Bulletin, 1961, 58, 234-255.

RACHMAN, $\mathrm{S}$. The role of muscular relaxation in desensitization therapy. Behavior Research and Therapy, 1968, 6, 159-166.

SchaCHTE R, J. Pain, fear, and anger in hypertensives and normotensives. Psychosomatic Medicine, 1957, 19, 17-29.

Spielberge R, C. D. Anxiety as an emotional state. In C. D. Spielberger (Ed.), Anxiety: Current trends in theory and research. New York: Academic Press, 1972.

Spielberger, C. D., Gorsuch, R. L., \& Lushene, R. E. STAI manual for the State-Trait Anxiety Inventory ("self-evaluation questionnaire"). Palo Alto, Calif: Consulting Psychologists Press, 1970.

Wenger, M. A. Pattern analysis of autonomic variables during rest. Psychosomatic Medicine, 1957, 19, 240-244.

(Received for publication January 26, 1980.) 